Original Research Paper

\title{
Bioactive Endophytic Actinomycetes of Cinnamomum sp.; Isolation, Identification, Activity Guided Purification and Process Optimization of Active Metabolite
}

\author{
${ }^{1}$ Sudipta Roy and ${ }^{2}$ Debdulal Banerjee \\ ${ }^{I}$ Department of Microbiology, Vidyasagar University, Midnapore-721102, West Bengal, India \\ ${ }^{2}$ Department of Botany and Forestry, Vidyasagar University, Midnapore-721102, West Bengal, India
}

\section{Article history}

Received: 10-12-2014

Revised: 04-02-2015

Accepted: 26-03-2015

Corresponding Author: Debdulal Banerjee Department of Botany and Forestry, Vidyasagar University, Midnapore-721102, West Bengal, India E-mail: debu33@gmail.com

\begin{abstract}
Studying on endophytic actinomycetes of Cinnamomum sp. from Indian rainforest, Cherapunji, one of our isolated strains designated as $\mathrm{CH} 1$ was found to produce significant antibacterial activity against test pathogens (Aeromonas caviae (ATCC 15468), Vibrio parahemolyticus ATCC 1782, Pseudomonas aeruginosa (ATCC 9027), Proteus vulgaris (ATCC 12453), Shigella flexnerii (ATCC 12022), Escherichia coli (human sample isolate), Bacillus subtilis (ATCC 11774) and Bacillus cereus (ATCC 14579). Scanning electron microscopic studies, morphological characterization and 16s ribosomal RNA gene sequence based classification strongly suggest that the isolate is a new strain of Streptomyces rochei. The rRNA gene sequenced was submitted to NCBI (GenBank accession number KJ486840.1). An antibacterial metabolite was extracted from fermented culture broth and purified by repeated silica gel column chromatography. TLC and bioautogram study of active fraction showed compound of Rf 0.196 was active metabolite where as HPLC study showed two major peak of RT 2.433 and $2.632 \mathrm{~min}$. Parameters influencing optimal antimicrobial production were also determined and the active compound was found nonmutagenic by Ames test. Based on above experiments it is concluded that this entophytic isolate can be further exploited for industrial and biological applications.
\end{abstract}

Keywords: Endophyte, Streptomyces, Antibacterial, Nonmutagenic, Optimization

\section{Introduction}

The emerging field of antimicrobial therapy in recent decades has cultivated much interest in using microbial natural products, such as toxins, proteins, hormones, vitamins and amino acids for diseases control (Fatope et al., 2000). These are virtually biodegradable, specific and generally have low toxicity (Newman et al., 2003). Finding of new antibiotics, which are effective against pathogenic bacteria, are an important area of antibiotic research. Actinobacteria are mainly soil bacteria, play an important role in biotechnological industries as it has the capability to produce a large number of antibiotics and other bioactive secondary metabolites (Roy and Banerjee, 2013). In recent years more than $90 \%$ antibiotics have obtained from actinobacteria and among which about $55 \%$ belong to the genus Streptomyces (Hamaki et al., 2005). Moreover, the multiplication in the number of drugresistant pathogens and the throttled success of strategies like combinatorial chemistry in providing new compounds indicate uncertainty for future antimicrobial therapy. Thus finding new groups of microbes from unexplored or less explored habitats became mandatory by pursuing them as sources of novel bioactive compounds. There are a variety of endophytic microorganisms inside the tissue of nearly all healthy plants. Endophytes are synergistic to their host; among them some are thought to be making returns for the nutrition from the plant by producing special substances, such as secondary metabolites. These metabolites protect the host from being attacked successfully by fungi and 
pests (Taechowisan et al., 2005). It has been found that some Streptomyces have taken up residence in plants which opens the possibility that, this may be an entirely prime source of novel pharmaceuticals (Joseph and Priya, 2011).

Tropical rainforests are vital to the global ecosystem and human existence. They are a world like no other and are unparalleled in terms of their biological diversity. During our study on endophytic bacteria from various plants of Cherapunji rainforest we have found a strain designated as $\mathrm{CH} 1$, isolated from Cinnamomum sp. (Lauraceae), showed potential antimicrobial property against some pathogenic bacteria. In this study we have identified the endophytic strain, described its antagonism to some selected pathogenic bacteria and purified its non-mutagenic bioactive metabolite. We have also determined various critical parameters that may influence rate of production of active substance.

\section{Materials and Methods}

\section{Isolation of Endophytic Actinomycetes}

Healthy stems of Cinnamomum were collected from the North-East Indian rainforest (Cherapunji, 25.30 $\mathrm{N}$ $91.70^{\circ} \mathrm{E}$ ) and brought in the laboratory in sterile ziplock bags. Stems were washed thoroughly under distilled water, soaked in autoclaved tissue paper and cut at about 0.5 to $1 \mathrm{~cm}$ in length. Surface sterilization of samples were made by using sodium hypochlorite and 70\% ethanol as surface sterilizing agent and then flame sterilized after dipping in $70 \%$ ethanol for 10 to $15 \mathrm{~s}$ to remove all epiphytic microorganisms (Zin et al., 2010). Barks were removed with sterile sharp blade and dissected plant stems were placed on various media for isolation of endophtyic actinomycetes. Water agar media, actinomycetes isolation agar media, glycerolasparagine agar media (ISP5) and yeast extract malt extract agar media (ISP2) supplemented with actidione $\left(50 \mu \mathrm{g} \mathrm{mL}^{-1}\right)$ were used for actinomycetes isolation in this study. Plates were incubated for at least 15 days at $28 \pm 2{ }^{\circ} \mathrm{C}$ (Lee et al., 2008). Actinomycete colonies emerging from stems were immediately brought in pure culture and preserved in $30 \%(\mathrm{v} / \mathrm{v})$ glycerol at $-20^{\circ} \mathrm{C}$.

\section{Antimicrobial Spectrum Analysis}

Antimicrobial property of isolates was checked against following pathogens on Muller Hinton agar media by agar diffusion method. Individual actinomycetes isolates were grown in liquid media (from where they were isolated) under shaking $(250 \mathrm{rpm})$ at 28 $+/-2^{\circ} \mathrm{C}$ for 10 days. Culture filtrate $(200 \mu \mathrm{L})$ was applied in the wells of MHA plates previously seeded with pathogens. Plates were incubated for $24 \mathrm{~h}$ and growth inhibition of pathogens were recorded. In this study Aeromonas caviae (ATCC 15468), Vibrio parahemolyticus ATCC 1782, Pseudomonas aeruginosa (ATCC 9027), Proteus vulgaris (ATCC 12453), Shigella flexnerii (ATCC 12022), Escherichia coli (human sample isolate from Medical College, Medinipur, WB, India), Bacillus subtilis (ATCC 11774), Bacillus cereus (ATCC 14579) were selected as test pathogens. Antibacterial potency of isolated bacteria was also compared with few known antibiotics against same pathogens under same condition. Endophytic isolate $\mathrm{CH} 1$ was selected due to its broad antibacterial spectrum and was further investigated.

\section{Morphological, Physiological and Biochemical Characterization}

CH1 was grown on ISP5 agar media and sterile coverslip was placed at $45^{\circ}$ angle at edge of its colony and further allowed to grow. Coverslip was taken out after 7 days and examined under bright field compound microscopy after Gram staining. Colony were further scrapped and studied for scanning electron microscopy (JEOL; JSM 5800, Japan) (Franson et al., 1984). Following standard methods aerial mycelium, spore mass color, substrate mycelium, pigmentation and if any diffusible pigment produced by the strain were recorded for the isolated strain (Shirling and Gottlieb, 1966; Williams et al., 1983). Different sugar utilization pattern was also determined (Gordon et al., 1974). Routine enzyme production by $\mathrm{CH} 1$ was checked for amylase, protease, lipase, cellulase and catalase by growing on specific media. Optimum growth temperature and $\mathrm{pH}$ was also determined after growing it in various temperature and $\mathrm{pH}$ conditions.

\section{DNA Isolation, Amplification and Sequencing of the 16S rRNA Gene}

Genomic DNA was isolated of the strain after growing in ISP5 broth for 5 days. Cells were taken in TE buffer (25 mM Tris-HCl [pH 8.0], $25 \mathrm{mM}$ EDTA and treated with lysoszyme, RNase and followed by $10 \%$ SDS. DNA was extracted with phenol- chloroformisoamyl alcohol and finally precipitated with isopropanol. 16S rRNA gene was amplified using the primers 27F (5'-AGA GTT TGA TCC TGG CTC AG3') and 1492R (5'-GGT TAC CTT GTT ACG ACT T3') (Santhi and Solomon, 2011). Reactions were performed on a thermocycler (Eppendorf) in $50 \mu \mathrm{L}$ volumes consisting of $2 \mu \mathrm{L}$ genomic DNA, $1.0 \mu \mathrm{M}$ each primer, $21 \mu \mathrm{L}$ sterile water and $25 \mu \mathrm{L}$ of REDTaq ReadyMix (HiMedia). Reaction parameters were as follows: Initial denaturation at $94^{\circ} \mathrm{C}$ for $5 \mathrm{~min}$ followed by 30 cycles of denaturation at $95^{\circ} \mathrm{C}$ for $60 \mathrm{sec}$, annealing at $55^{\circ} \mathrm{C}$ for $60 \mathrm{sec}$ and extension at $72^{\circ} \mathrm{C}$ for $90 \mathrm{sec}$. A final extension was done at $72^{\circ} \mathrm{C}$ for $10 \mathrm{~min}$. PCR products were purified with Hi-PurA ${ }^{\mathrm{TM}}$ PCR product purification spin kit (Himedia). Forward and reverse DNA 
sequencing reactions of purified PCR amplicon was carried out with same primers using BDT v3.1 Cycle sequencing kit on ABI 3730xl Genetic Analyzer.

\section{Phylogenetic Analysis}

Consensus sequence of 1397 bp rRNA gene was generated from forward and reverse sequence data using aligner software. The 16S rDNA gene sequence was used to carry out BLAST with the 'nr' database of NCBI genbank. Based on maximum identity score sequences were selected and aligned using multiple alignment software program, Clustal W. Distance matrix was generated using RDP (Ribosomal Database Project) database and the phylogenetic tree was constructed using MEGA 6 (Tamura et al., 2007). The evolutionary history was inferred using the NeighborJoining method (Saitou and Nei, 1987). The evolutionary distances were computed using the Kimura 2-parameter method (Kimura, 1980).

\section{Nucleotide Sequence Accession Numbers}

DNA sequences were deposited in GenBank under accession number KJ486840.1

\section{Production and Extraction of Bioactive Metabolite}

$\mathrm{CH} 1$ grown agar block (surface area $1 \mathrm{~cm}^{2}$ ) was aseptically transferred to $100 \mathrm{~mL}$ Erlenmeyer flask containing $30 \mathrm{~mL}$ ISP5 broth and incubated at $28^{\circ} \mathrm{C}$ for $72 \mathrm{~h}$ at $250 \mathrm{rpm}$ for seed production. Seed culture was inoculated $(5 \% \mathrm{v} / \mathrm{v})$ into $250 \mathrm{~mL}$ Erlenmeyer flask containing $60 \mathrm{~mL}$ production media having composition bacto-tryptone $5 \mathrm{~g} \mathrm{~L}^{-1}$, dextrose $10 \mathrm{~g} \mathrm{~L}^{-1}$, yeast extract $2 \mathrm{gm} \mathrm{L}^{-1}, \mathrm{~K}_{2} \mathrm{HPO}_{4} 2 \mathrm{~g} \mathrm{~L}^{-1}, \mathrm{NaCl} 2 \mathrm{~g} \mathrm{~L}^{-1}$ and $\mathrm{MgSO}_{4}, 7 \mathrm{H}_{2} \mathrm{O} 500 \mathrm{mg} \mathrm{L}^{-1}$ and cultured for 12 days at $28^{\circ} \mathrm{C}$ in orbital shaking at $250 \mathrm{rpm}$. After fermentation total $1.8 \mathrm{~L}$ culture broth was filtered through Whatman paper no. 1 and then centrifuged at $14,000 \mathrm{x} \mathrm{g}$ for $20 \mathrm{~min}$ to remove any cell mass. The culture filtrate was then extracted twice with equal volume of ethyl acetate. This organic solvent extract was pooled, made water free by adding anhydrous $\mathrm{Na}_{2} \mathrm{SO}_{4}$ and then taken to dryness under vacuum in rotary evaporator (HS-2005S, HAHNSHIN, Korea) at $40^{\circ} \mathrm{C}$. Residual part was dissolved in $2 \mathrm{ml}$ methanol.

\section{Purification by Flash Column Chromatography}

The methanolic extract was soaked in silica gel and loaded onto the silica gel column (230-400 ̊̊ mesh size). Extract was eluted first with $50 \mathrm{~mL}$ hexane- chlororform (50:0, 4:1, 1:1,1:4, 0:50) of increasing polarity and then with chloroform- methanol $(50: 0,48: 2,45: 5,40: 10$, $25: 25,10: 40,0: 50)$. All collected fractions were concentrated to $2 \mathrm{ml}$ and tested for antimicrobial activity by disk diffusion method ( $25 \mu \mathrm{L}$ disk content) against $B$ cereus and $E$ coli. The active fraction was again purified by silica gel column with chloroform- methanol of more finely graded solvent system (chloroform and methanol: 50:0, 49.5:0.5, 49:1, 48.5:1.5, 48:2, 47.5:2.5, 45:5, 0:50). The eluting volume for this time was fixed to $25 \mathrm{~mL}$. Different fractions were concentrated to $1 \mathrm{~mL}$ and bioactivity was determined similarly.

\section{HPLC and Activity Guided TLC Study of Active Fraction}

Ten micro liters of most the active fraction was analyzed in reverse phase high performance liquid chromatography (Agilnet, 1260, USA) under the following conditions: Flow rate $1.0 \mathrm{~mL} \mathrm{~min}^{-1}$; stationary phase Delta Pak C18 column (Zorbax high purity porous silica microsphere); $23^{\circ} \mathrm{C}$; mobile phase $80 \%$ methanol in chloroform; detector wavelength $260 \mathrm{~nm}$. Numbers of peaks with their retention time were recorded.

Five micro liters active fraction was spotted on silica coated alumina TLC plate as thin band and was separated using chloroform-methanol (20:1) followed by UV detection. For bioautogram study, after UV detection, TLC plate was covered with a layer of MHA $\left(40^{\circ} \mathrm{C}\right)$ containing $B$. cereus $\left(50 \mu \mathrm{L}\right.$ of $\left.10^{5} \mathrm{cfu} \mathrm{mL}^{-1}\right)$ and incubated for $24 \mathrm{~h}$ at $35^{\circ} \mathrm{C}$. Cell viability was checked by spraying methylthiazoletetrazolium (MTT-5 mg mL ${ }^{-1}$ ) on pathogen grown media surface. Inhibition zone was observed as clear spots against a purple background.

\section{Mutagenic Potentiality Test of Active Compound}

Salmonella typhimurium TA100 was used for this experiment. This bacterium has point mutations in the histidine ( $h i s$ ) operon, rendering it being incapable of producing histidine. When a mutagenic event occurs, base substitutions or frameshifts within his gene may cause a reversion to histidine prototrophy. Ames mutagenicity assay was performed for purified compound exposing directly and with S9 liver extract activation to the test bacteria. Strain TA 100 was first grown on LB media supplemented with $10 \mathrm{mg} \mathrm{mL}^{-1} \mathrm{His}$ and $1 \mathrm{mg} \mathrm{mL}^{-1}$ biotin. Approximately $90 \mu \mathrm{L}$ aliquot $\left(10^{6}\right.$ cfu $\left.\mathrm{mL}^{-1}\right)$ was mixed with $10 \mu \mathrm{L}$ His-Bio solution $(0.5$ $\mathrm{mM}$ ) and seeded on Glucose Minimal agar media. Purified sample (15 and $50 \mu \mathrm{L})$ was soaked on sterile filter paper disk and with $100 \mu \mathrm{L} \mathrm{S} 9$ liver extract at $37^{\circ} \mathrm{C}$ separately. Negative control was made with methanol $(50 \mu \mathrm{L})$ and positive control with $\mathrm{NaN}_{3}$ (1 $\mu \mathrm{L}$ from stock-1 $\mu \mathrm{g} \mathrm{mL}^{-1}$ ) soaked paper disk. Paper disks were placed centrally on TA 100 inoculated plates and incubated at $37^{\circ} \mathrm{C}$ for $24 \mathrm{~h}$. Well developed revertant bacterial colony were counted and analyzed. The compound was judged to be mutagenic if the number of revertants were 2 folds or more relative to the negative control (Rodríguez et al., 2012). 
Optimization of Anitmicrobial Production by Regulating Various Influencing Parameters

Species-specific variation occurs within Streptomyces for cell growth and production of secondary metabolites by the influences of various factors (Vilches et al., 1990; Kojima et al., 1995). In our experiment we have carefully regulated several cultural parameters to determine optimum production of the bioactive compound. Firstly ISP5 broth, TYG broth, mineral salt broth and SCN broth were checked for maximum antimicrobial production. Optimum incubation period was determined by growing $\mathrm{CH} 1 \mathrm{up}$ to 15 days in TYG broth and culture supernatant was verified for antibacterial activity against $B$. cereus. Most desirable carbon and nitrogen source for optimum antimicrobial production were also evaluated. Dextrose, fructose, galactose, maltose, lactose, sucrose $(1 \% \mathrm{w} / \mathrm{v})$ were used as various carbon source and peptone, tryptone, soymeal, casein $(0.5 \%$ w/v), $\mathrm{KNO}_{3}, \mathrm{NaNO}_{3}, \mathrm{NH}_{4} \mathrm{Cl}$, urea and $\mathrm{L}$-Asn $(0.2 \%$ $\mathrm{w} / \mathrm{v}$ ) were taken individually as sole nitrogen in TYG broth. Initial $\mathrm{pH}$ variation of media $(\mathrm{pH}-4,6,7,8$ and 10) was also checked to determine optimum $\mathrm{pH}$ for antimicrobial production.

\section{Results}

Endophytic isolate, $\mathrm{CH} 1$ was isolated on ISP 5 agar media. The light microscopic characterization of $\mathrm{CH} 1$ depicts that it is branched filamentous Gram positive bacteria. SEM study reveals its spore orientation as oval 3-8 spores of about 1 to $1.2 \mu \mathrm{m}$ diameter, at tip of the filaments (Fig. 1). CH1 produces elevated chalky, dry, irregular folding white colony on ISP5 agar media. Other morphological and physiochemical properties of strain $\mathrm{CH} 1$ was summarized in Table 1. 16s rRNA sequences and phylogeny study showed close relationship between $\mathrm{CH} 1$ and various type strains of Streptomyces rochei (Fig. 2). It showed 99\% 16s rDNA sequence similarity with different type strains of Streptomyces rochei like SCSIOZ-SH06, SCSIOZ-SH07, cfcc3115, SCSIOZ$\mathrm{SH} 12$ etc. We propose our isolated strain $\mathrm{CH} 1$ as Streptomyces rochei $\mathrm{CH} 1$ according to its rDNA sequences and other characterization similarities (Acharyabhatta et al., 2013; Ma et al., 2008) though it shows similar rRNA sequences homology to few other species of Streptomyces.

Antimicrobial assay of $\mathrm{CH} 1$ culture filtrate against test pathogens represents its potential antibacterial spectrum though it does not inhibit Pseudomonas aeruginosa at all (Table 2). The appearance of evaporated residual was amorphous dark brownish. Active antibacterial compound was eluted with chloroform: Methanol $(47: 1.5)$ that showed highest antibacterial activity. Thin layer chromatogram of this fraction indicates two distinct bands $\mathrm{X}$ and $\mathrm{Y}$ of rf value of 0.196 and 0.410 respectively. Bioautogram study revealed compound X ( $\mathrm{rf}$ value of 0.196 ) to be active antibacterial secondary metabolite produced by this strain. The active extract was further analyzed by analytical reverse phase HPLC with a $\mathrm{C}^{18}$ column based on hydrophobicity. Two major compounds were found with retention time 2.433 and 2.632 min respectively (Fig. 3) among which compound with RT-2.632 was most abundant which might be the active substance.

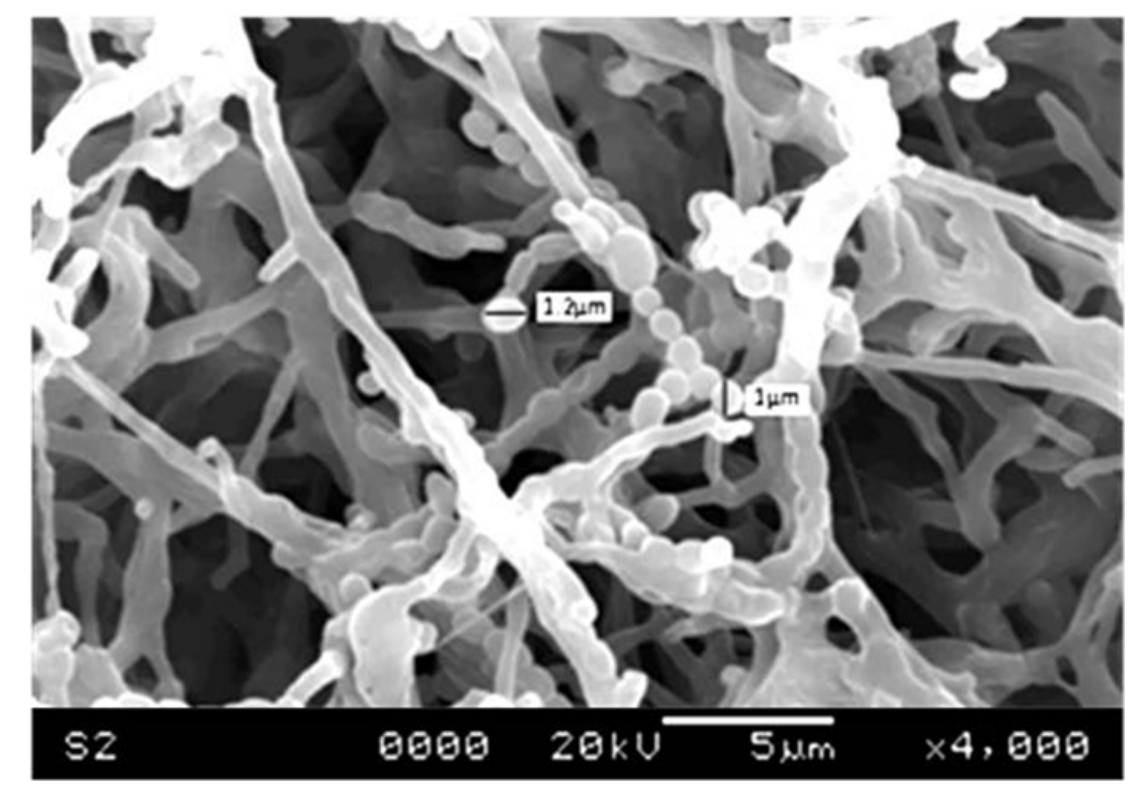

Fig. 1. Highly branched mycellial structure with spore of Streptomyces rochei CH1 


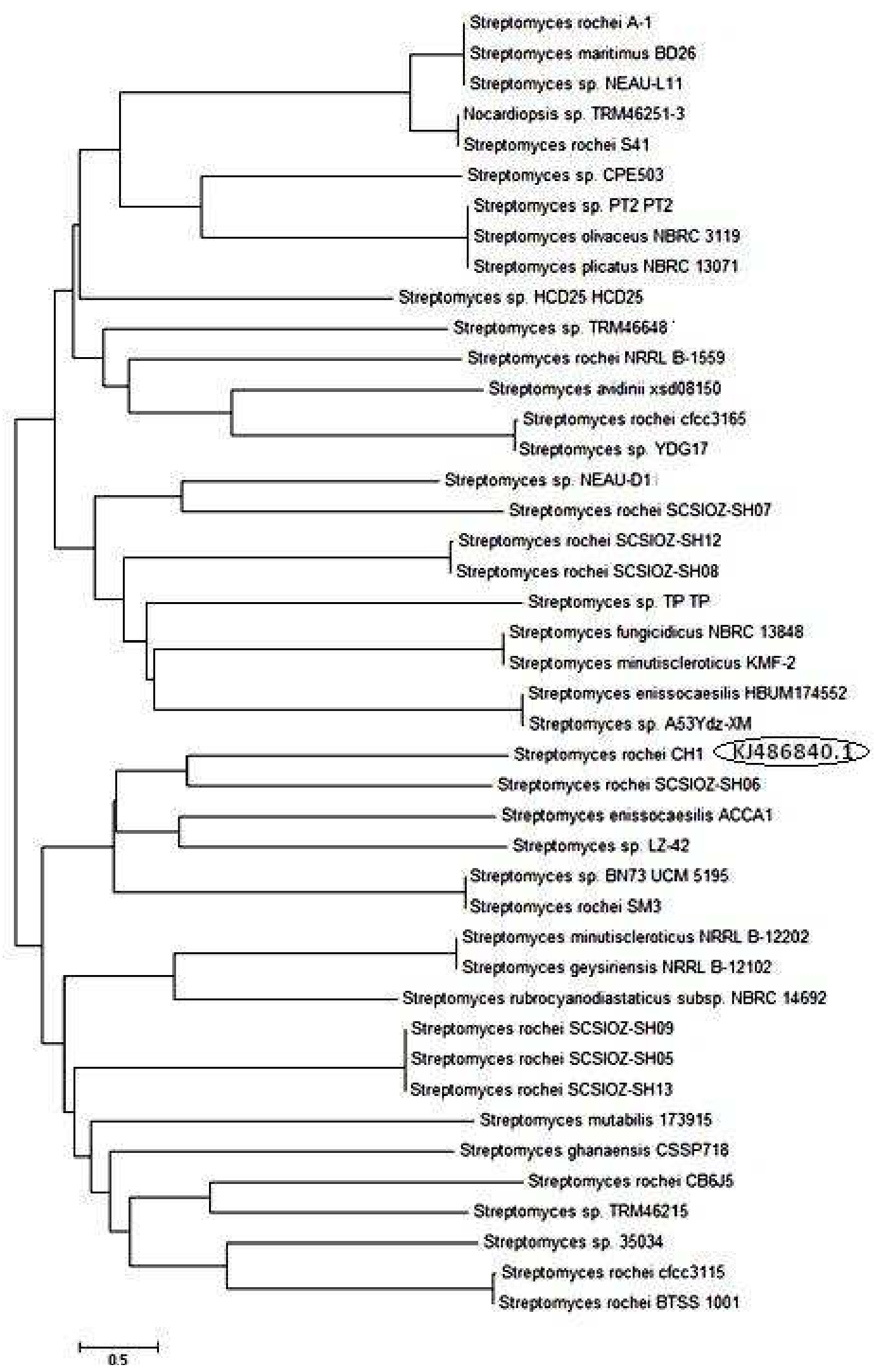

Fig. 2. Phylogenetic position of Streptomyces rochei CH1 using 16S rRNA partial sequences 
Table 1. Characterization of Streptomyces rochei CH1

Colony morphology (ISP5)

\section{Cultural morphology}

Growth on ISP2

Substrate mycelia

Aerial mycelia

Growth on ISP4

Substrate mycelia

Aerial mycelia

Growth of ISP5

Substrate mycelia

Aerial mycelia

Growth on ISP7

Substrate mycelia

Aerial mycelia

Starch Casein Nitrate agar (SCN)

Substrate mycelia

Aerial mycelia

Pigmentation

Diffusible pigment

Melanoid pigment (ISP1, 6, 7)

Cellular and spore morphology

Vegetative cells

Spore per chain

Spore shape

Spore surface

Spore size

Gram characetr

Extra cellular enzymes

Cellulase

Amylase

Lipase

Protease

Catalse

\section{Carbon source utilization}

Dextrose

Fructose

Galactose

Lactose

Maltose

Sucrose

Starch

Mannitol

Growth parameters

Temperature

pH

Highly branched filamentous

3-8 spores at tip of the filaments

Round to oval

Smooth and hairy surface

About 1 to $1.2 \mu \mathrm{m}$ diameter

Positive

$$
\begin{aligned}
& + \\
& + \\
& + \\
& - \\
& + \\
& \\
& + \\
& + \\
& + \\
& + \\
& + \\
& + \\
& + \\
& +
\end{aligned}
$$

$20-40^{\circ} \mathrm{C}\left(28^{\circ} \mathrm{C}\right.$ optimum $)$

6-10 (optimum pH 8)

Table 2. Antibacterial activity of $S$. rochei $\mathrm{CH} 1$ fermented crude liquor

\begin{tabular}{llcccr}
\hline Test pathogens & $\begin{array}{l}\text { Mean zone } \\
\text { diameter }(\mathrm{mm})^{*}\end{array}$ & $\begin{array}{c}\text { Penicillin-G } \\
(1 \mathrm{UI})\end{array}$ & $\begin{array}{c}\text { Ampicillin } \\
(25 \mu \mathrm{g})\end{array}$ & $\begin{array}{c}\text { Streptomycin } \\
(25 \mu \mathrm{g})\end{array}$ & $\begin{array}{c}\text { Co-trimoxazole } \\
(25 \mu \mathrm{g})\end{array}$ \\
\hline Aeromnas cavie & 16.33 & 12.00 & 15.50 & 34.83 & 19.50 \\
Aeromonas hydrophila & 16.33 & 14.83 & 18.66 & 31.00 & 18.50 \\
Vibrio parahemolyticus & 15.83 & 10.50 & 17.50 & 34.66 & 15.33 \\
Pseudomonas aeruginosa & - & - & - & 25.50 & 13.83 \\
Proteus vulgaris & 14.66 & 15.66 & 17.66 & 33.66 & 16.00 \\
Shigella flexnerii & 13.83 & 12.16 & 16.00 & 34.83 & 24.00 \\
Escherichia coli & 16.50 & 11.33 & 18.00 & 26.16 & 18.50 \\
Bacillus subtilis & 23.16 & 35.83 & 46.50 & 36.16 & 24.66 \\
Bacillus cereus & 24.00 & 37.50 & 45.00 & 32.50 & 26.83 \\
\hline
\end{tabular}

(* Results are represented as means of three replicates) 
Many of such antimicrobial secondary metabolites possess various toxic effects to human health. A basic study for evaluation of mutagenic potentiality of compound is Ames test. After $48 \mathrm{~h}$ no significant increases in colony numbers were found for the sample of interest when compared to spontaneously reverted plate. $\mathrm{NaN}_{3}$ added plate result more than double colony number than spontaneous reversion as usual (Fig. 4).

Present study was carried out for optimum production of antimicrobial compound from strain $\mathrm{CH} 1$. It was found that TYG broth as most suitable media for antimicrobial production from Streptomyces rochei $\mathrm{CH} 1$. Antimicrobial production in salt media was very poor that may indicate organic nitrogen and carbon is essential for antimicrobial production. Most effective nitrogen source for antimicrobial production was found to be tryptone and dextrose as effective carbon source, though considerable antimicrobial production was observed with lactose. Less activity was found when peptone, used as organic nitrogen source but surprisingly no other organic or inorganic salt played role in antimicrobial production. It was found that antimicrobial production had started at 6th day of incubation as in early hours actiniomycete growth remains in lag phase and secondary metabolite production usually starts at late log phase. Antimicrobial production was found to be highest at 12th day. Strain $\mathrm{CH} 1$ was found to produce highest antibacterial activity at initial media $\mathrm{pH}$ 7. All the optimization data are depicted in Fig. 5.

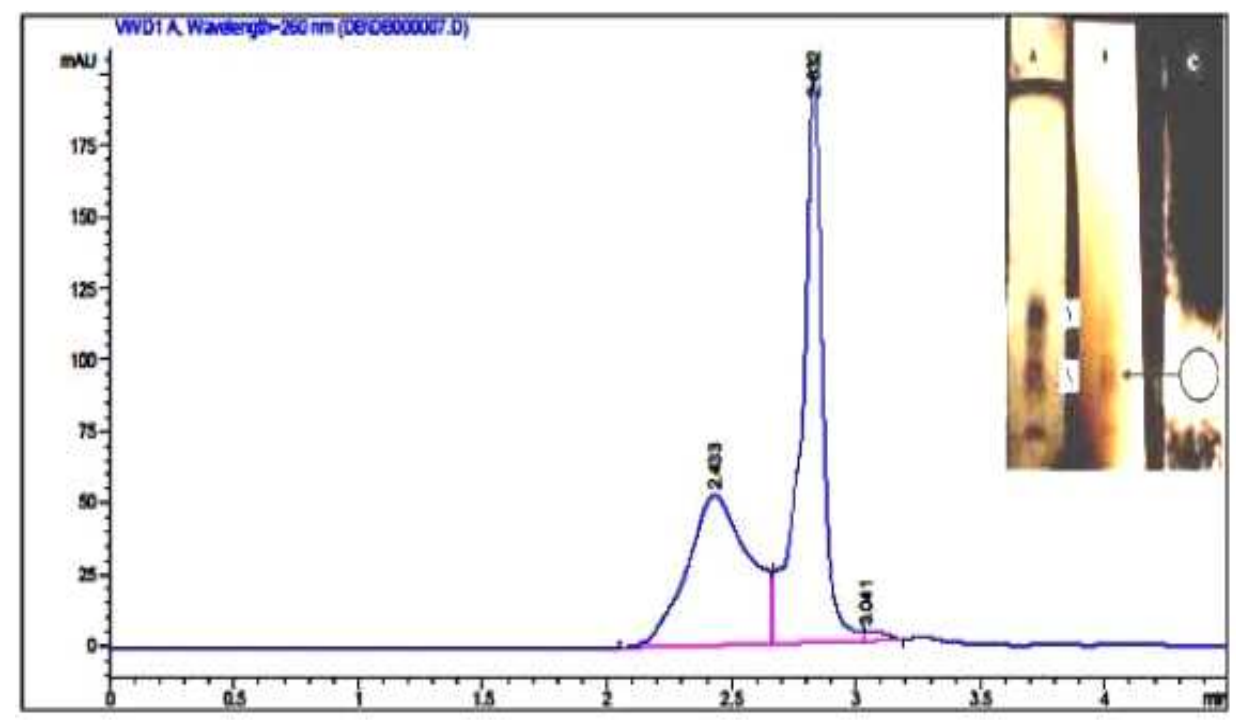

Fig. 3. HPLC analysis of column purified active secondery metabolite. (Inset; TLC and bioautogram of active fraction, A-UV exposed, B-iodine vapour, C-autobiogram (circle indicates dead cells and arrow, corresponding band)

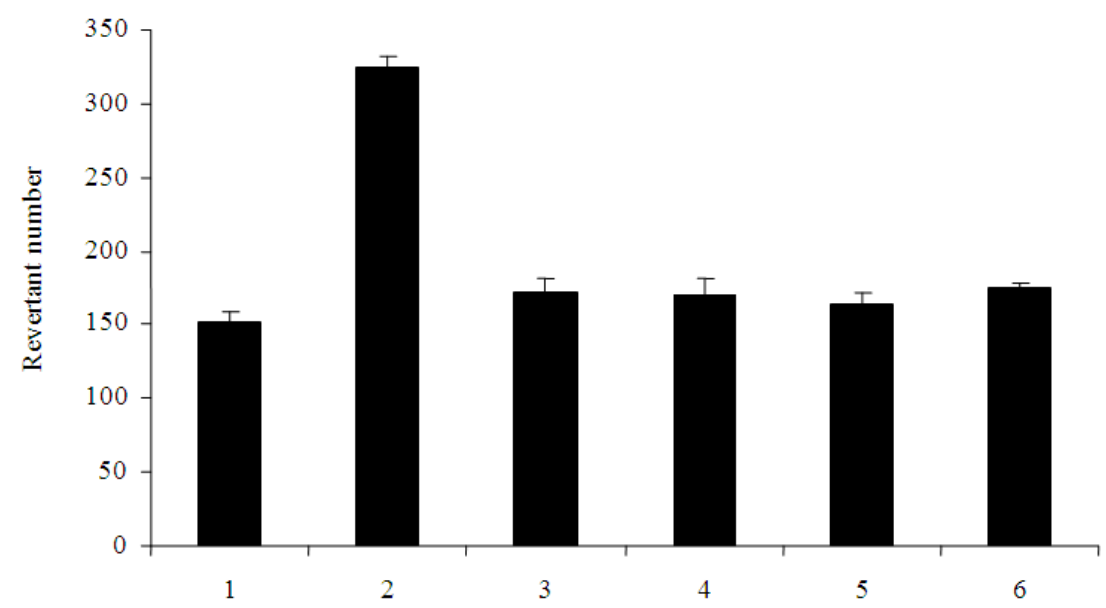

Fig. 4. Ames mutagenecity test of purified bioactive compound; 1-spontaneous reversion, 2-NaN3 control, 3-purified extract15 $\mu \mathrm{L}$, 4-purified extract $50 \mu \mathrm{L}, 5$-purified extract $15 \mu \mathrm{L}+\mathrm{S} 9$, 6-purified extract $50 \mu \mathrm{L}+\mathrm{S} 9$ (values represent mean of three replicates and error bar as sd from mean) 


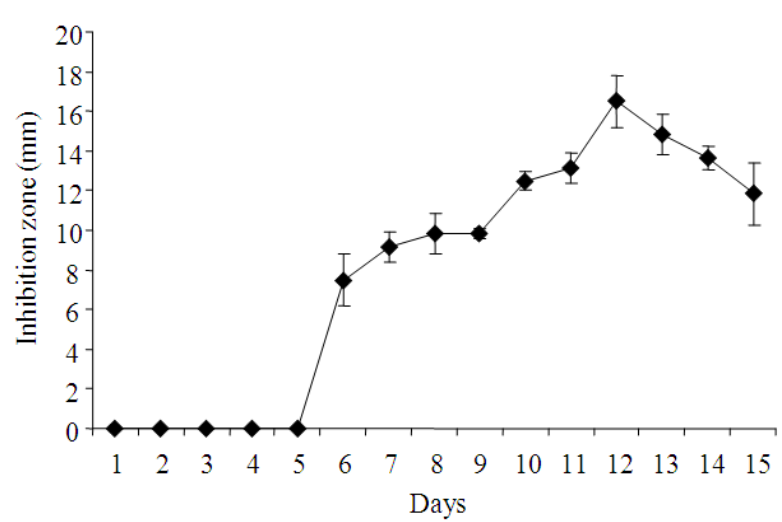

(A)

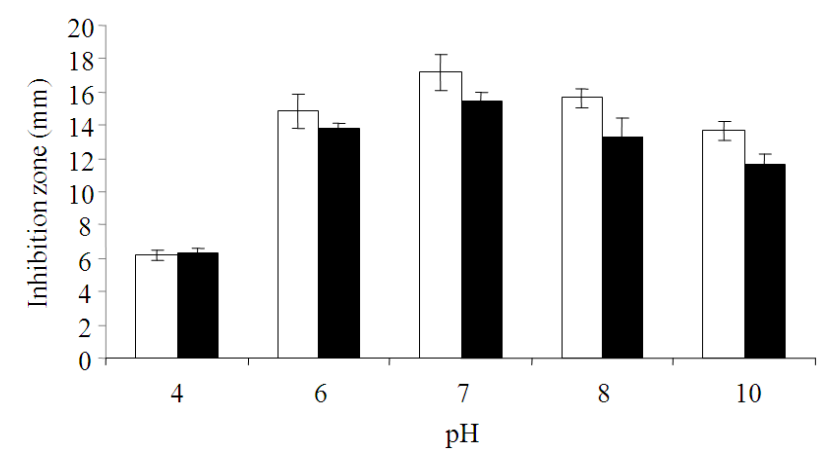

(C)

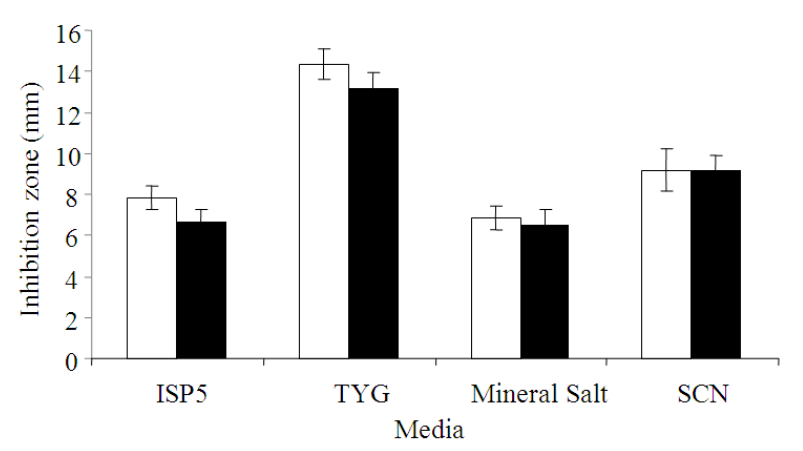

(B)

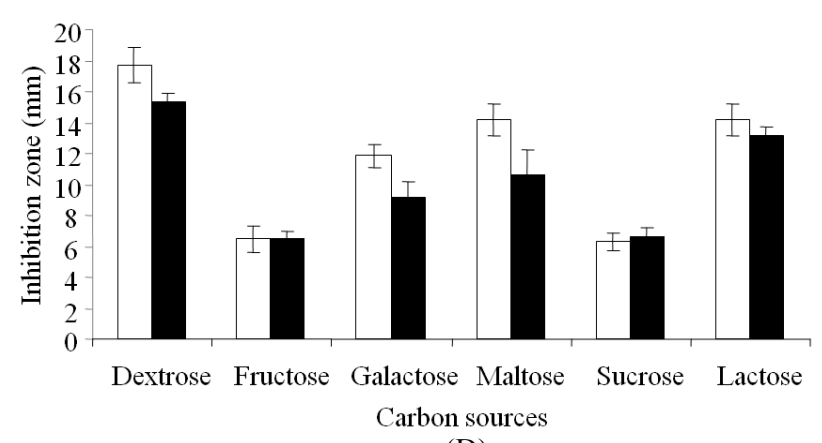

(D)

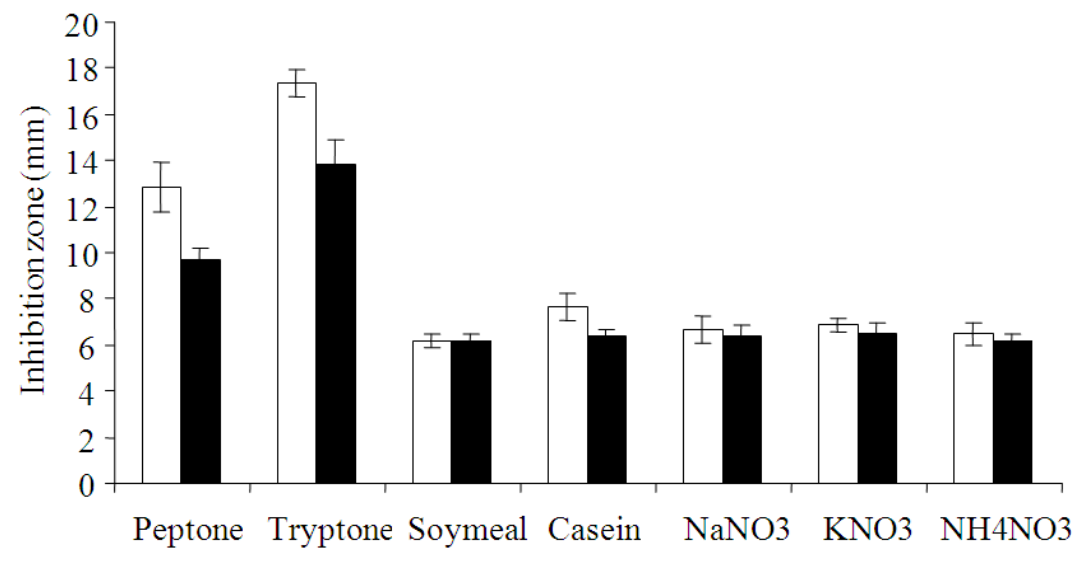

Nitrogen sources

(E)

Fig. 5. Characterization of parameters for optimum production of bioactive compound against B. cereus. (A) Incubation period (B) Media type (C) Initial pH of media (D) Carbon source type (E) Nitrogen source type. (values represent mean of 3 replicates and error bars used as sd from mean)

\section{Discussion}

Most of the endophytic Streptomyces so far isolated are good anti fungal producers but less report are found where they are lethal to bacteria (Zin et al., 2007). Streptomyces rochei BTSS 1001 a marine actinomyceyes with alkaline amylolytic activity (Acharyabhatta et al.,
2013) was found to be similar cultural properties with strain $\mathrm{CH} 1$ but exceptionally it does not grow well at ISP2 and no pigmentation was found in any media. Ma et al. (2008) reported endophytic actinomycetes Lj20 producing butylated hydroxytoluene and 3, 5-di-tertbutyl-4-hydroxybenzyl methyl ether as its secondary metabolite with significant antifungal activity. 
Streptomyces rochei is known to produce Lankacidin and Lankamycin group of antibiotic and $\gamma$ Butyrolactone, a diffusible signaling molecule, often regulate antibiotic production and/or morphogenesis in this bacterium (Yamamoto et al., 2008). Streptomyces rochei F20, non-endophytic actinomycetes is also reported for production of streptothricin class antibiotics (Anukool et al., 2004). However this is the first report of endophytic Streptomyces rochei with potential antibacterial activity isolated from Cinnamomum of Indian rain forest.

In our experiment we have extensively characterized this bacterium from physical, biochemical and molecular aspect. This isolated strain produced antimicrobial substance which is comparable with penicillin, ampicillin, streptomycin and co-trimoxazole to some extent. The active compound was purified by flash column chromatography which was confirmed by TLC analysis and bioautogram studies. Genetic diversity very often is responsible for production of new class antibiotics. Chance of some genetic diversity is higher in co-evolutionary endophytic relationship lead to the ability for biosynthesizing some unusual compound different from its other strains of different ecological niche by genetic variation; including uptake of some plant DNA in their self genome (Germaine et al., 2004; Stierle et al., 1993). Moreover no mutagenic property of purified bioactive metabolite was found in any concentration and combination tested in this study which indicates its potential applicability as drug. So, further structural characterization of active compound is necessary for this endophytic strain.

\section{Conclusion}

The isolated enophytic strain was identified as new strain of Streptomyces rochei CH1 (GenBank KJ486840.1). This specific strain exhibits broadspectrum of non-mutagenic antimicrobial activity which is active against both Gram positive and Gram negative pathogens. Optimizations for antimicrobial production conditions and other significant results may help to exploit this strain in future drug.

\section{Acknowledgement}

Authors are thankful to University Grants Commission (UGC), New Delhi for funding, SR is thankful to Oriental Institute of Science and Technology (OIST) for their help during this work.

\section{Author's Contributions}

All authors equally contributed in this work.

\section{Ethics}

This article is original and contains unpublished material. The corresponding author confirms that all of the other authors have read and approved the manuscript and no ethical issues involved.

\section{References}

Acharyabhatta, A., S.K. Kandula and R. Terli, 2013. Taxonomy and polyphasic characterization of alkaline amylase producing marine actinomycete Streptomyces rochei BTSS 1001. Int. J. Microbiol., 1-8. DOI: $10.1155 / 2013 / 276921$

Anukool, U., W.H. Gaze and E.M.H. Wellington, 2004. In situ monitoring of streptothricin production by Streptomyces rochei F20 in soil and rhizosphere. Appl. Env. Microbiol., 70: 5222-5228, DOI: 10.1128/AEM.70.9.5222-5228.2004

Fatope, M.O., O.A. Adoum and Y. Takeda, 2000. $\mathrm{C}_{18}$ acetylenic fatty acids of Ximenia americana with potential pesticidal activity. J. Agri. Food Chem., 48: 1872-1874. DOI: 10.1021/jf990550k

Franson, T.R., N.K. Sheth, H.D. Rose and P.G. Sohnle, 1984. Scanning electron microscopy of bacteria adherent to intravascular catheters. J. Clin. Microbiol., 20: 500-505.

Germaine, K., E. Keogh, C.G. Garcia, B. Borremans and D. van der Lelie et al., 2004. Colonisation of poplar trees by $g f p$ expressing bacterial endophytes. FEMS Microbiol. Ecol., 48: 109-118.

DOI: 10.1016/j.femsec.2003.12.009

Gordon, R.E., D.A. Barnett, J.E. Handerhan and C.H.N. Pang, 1974. Nocardia coeliaca, Nocardia autotrophica and the Nocardin strain. Int. J. Syst. Evol. Microbiol., 24: 54-63.

DOI: 10.1099/00207713-24-1-54

Hamaki, T., M. Suzuki, R. Fudou, Y. Jojima and T. Kajiura et al., 2005. Isolation of novel bacteria and actinomycetes using soil-extract agar medium. J. Biosc. Bioeng., 99: 485-492. DOI: $10.1263 /$ jbb.99.485

Joseph, B. and R.M. Priya, 2011. Bioactive compounds from endophytes and their potential in pharmaceutical effect: A review. Am. J. Biochem. Mol. Biotechnol., 1: 291-309. DOI: 10.3923/ajbmb.2011.291.309

Kimura, M., 1980. A simple method for estimating evolutionary rates of base substitutions through comparative studies of nucleotide sequences. J. Mol. Evol., 16: 111-120. DOI: 10.1007/BF01731581

Kojima, I., Y.R. Cheng, V. Mohan and A.L. Demain, 1995. Carbon source nutrition of rapamycin biosynthesis in Streptomyces hygroscopicus. J. Ind. Microbiol., 14: 436-439.

DOI: $10.1007 / \mathrm{BF} 01573954$ 
Lee, O., G.J. Choi, Y.H. Choi, K.S. Jang and D.J. Park et al., 2008. Isolation and characterization of endophytic actinomycetes from Chinese cabbage roots as antagonists to Plasmodiophora brassicae. J. Microbiol. Biotechnol., 18: 1741-1746. PMID: 19047815

Ma, L., H. Chen, J. Han and H. Liu, 2008. Identification of endophytic Actinomycete $\mathrm{Lj} 20$ from plant and its antifungal substances. Acta Microbiologica Sinica, 48: 900-904. PMID: 18837367

Newman, D.J., G.M. Cragg and K.M. Snader, 2003. Natural products as sources of new drugs over the period 1981-2002. J. Nat. Prod., 66: 1022-1037. DOI: $10.1021 / \mathrm{np} 0300961$

Rodríguez, E., C. Piccini, V. Sosa and P. Zunino, 2012. The use of the Ames test as a tool for addressing problem-based learning in the microbiology lab. J. Microbiol. Biol. Educ., 13: 175-177.

DOI: $10.1128 /$ jmbe.v13i2.421

Roy, S. and D. Banerjee, 2013. Actinomycetes-the Most Promising Reservoir of Novel Class of Antimicrobial Compounds. In: Microbiology Applications, Rath, C.C. (Ed.), Bhalla and Sons, India, ISBN-10: 978-81-905771-3-7, pp: 49-63.

Saitou, N. and M. Nei, 1987. The neighbor-joining method: A new method for reconstructing phylogenetic trees. Mol. Biol. Evol., 4: 406-425.

Santhi, V.S. and R.D.J. Solomon, 2011. Phylogenetic analysis and antimicrobial activities of Streptomyces isolates from mangrove sediment. J. Basic Microbiol., 51: 71-79.

DOI: $10.1002 /$ jobm. 201000107

Shirling, E.B. and D. Gottlieb, 1966. Methods for characterization of Streptomyces species. Int. J. Systematic Evolut. Microbiol., 16: 313-340. DOI: 10.1099/00207713-16-3-313

Stierle, A., G. Strobel and D. Stierle, 1993 Taxol and taxane production by Taxomyces andreanae, an endophytic fungus of Pacific yew. Science, 260: 214-216. DOI: 10.1126/science.8097061
Taechowisan, T., C. Lu, Y. Shen and S. Lumyong, 2005. Secondary metabolites from endophytic Streptomyces aureofaciens CMUAc130 and their antifungal activity. Microbiology, 151: 1691-1695. DOI: $10.1099 /$ mic.0.27758-0

Tamura, K., J. Dudley, M. Nei and S. Kumar, 2007. MEGA4: Molecular Evolutionary Genetics Analysis (MEGA) software version 4.0. Mol. Biol. Evol., 24: 1596-1599. DOI: $10.1093 / \mathrm{molbev} / \mathrm{msm} 092$

Vilches, C., C. Méndez, C. Hardisson and J.A. Salas, 1990. Biosynthesis of oleandomycin by Streptomyces antibioticus: Influence of nutritional conditions and development of resistance. Microbiology, 136: 1447-1454. DOI: 10.1099/00221287-136-8-1447

Williams, S.T., M. Goodfellow, G. Alderson, E.M.H. Wellington and P.H.A. Sneath et al., 1983. Numerical classification of Streptomyces and related genera. Microbiology, 129:1743-1813. DOI: $10.1099 / 00221287-129-6-1743$

Yamamoto, S., Y. He, K. Arakawa and H. Kinashi, 2008. $\gamma$-Butyrolactone-dependent expression of the Streptomyces antibiotic regulatory protein gene $\operatorname{srr} Y$ plays a central role in the regulatory cascade leading to lankacidin and lankamycin production in Streptomyces rochei. J. Bacteriol., 190: 1308-1316. DOI: $10.1128 / \mathrm{JB} .01383-07$

Zin, N.M., M.N.I. Sarmin, N. Ghadin, D.F. Basri and N.M. Sidik et al., 2007. Bioactive endophytic streptomycetes from the Malay Peninsula. FEMS Microbiol. Lett., 274: 83-88. DOI: $10.1111 /$ j.1574-6968.2007.00819.x

Zin, N.M., C.S. Loi, M.N. Sarmin and A.N. Rosli, 2010. Cultivation-dependent characterization of endophytic actinomycetes. Res. J. Microbiol., 5: 717-724. DOI: 10.3923/jm.2010.717.724 